\title{
El salario mínimo en México: Aspectos económicos del año 2016
}

\section{The minimum wage in Mexico: Economic aspects of 2016}

\author{
DOI: $10.46932 / \mathrm{sfjdv3n1-056}$
}

Received in: Jan 30st, 2021

Accepted in: Feb 1th, 2022

\section{Dr. Saúl Robles Soto}

Docente-Investigador de la Unidad Académica de Economía de la Universidad Autónoma de Zacatecas, México

E-mail: saul.robles@ymail.com

\section{RESUMEN}

El Presente trabajo de investigación se refiere al salario mínimo en México en los últimos años que no corresponde a las exigencias de la clase trabajadora que requiere de una retribución adecuada a las labores que desarrolla. Se realiza una revisión de la evolución en el período 2012-2016, que se ha caracterizado por una especie de abandono a un segmento de la población obrera que percibe un salario mínimo que es de los más bajos del mundo según diversos organismos especializados en el tema como la OCDE, el Banco Mundial y la Academia en México. Los datos que se presentan en el trabajo estuvieron apoyados por el Laboratorio de Economía Aplicada (LEA) de la Unidad Académica de Economía de la Universidad Autónoma de Zacatecas (UAEUAZ), México, en base a investigaciones periódicas que se realizan en diversos ámbitos de la ciencia económica para tratar de incidir en la medida de lo posible con alternativas de solución a la grave situación que padecen más de 8.5 millones de trabajadores que realizan cotidianamente un sinfín de malabares para agrandar un salario que es a todas luces muy raquítico. Asimismo, se especifican datos duros de la realidad que viven dichos trabajadores que siguen esperando los beneficios tantas veces prometidos de una clase política que en el discurso es muy elocuente en cuanto a resolver la problemática económica de México, pero que en los hechos se demuestra una y otra vez que el salario mínimo en el país sigue siendo una piedra en el zapato para las autoridades federales.

Palabras claves: México, salario mínimo, desigualdad, crecimiento económico, bienestar.

\begin{abstract}
The present research work refers to the minimum wage in Mexico in recent years, which does not correspond to the demands of the working class that requires adequate remuneration for the work it performs. A review is made of the evolution in the period 2012-2016, which has been characterized by a kind of abandonment to a segment of the working population that receives a minimum wage that is among the lowest in the world according to various organizations specialized in the subject such as the OECD, the World Bank and the Academy in Mexico. The data presented in the paper were supported by the Laboratory of Applied Economics (LEA) of the Academic Unit of Economics of the Autonomous University of Zacatecas (UAEUAZ), Mexico, based on periodic research conducted in various fields of economic science to try to influence as far as possible with alternative solutions to the serious situation suffered by more than 8.5 million workers who daily make endless juggling to increase a salary that is clearly very rickety. Likewise, hard data is specified on the reality of the workers who continue to wait for the benefits so many times promised by a political class that in its discourse is very eloquent in terms of solving Mexico's economic problems, but in practice it is demonstrated time and again that the minimum wage in the country continues to be a stone in the shoe of the federal authorities.
\end{abstract}


Keywords: Mexico, minimum wage, inequality, economic growth, welfare.

\section{PRESENTACIÓN}

Una de las principales variables de todo sistema económico lo constituye el salario que perciben los trabajadores. Una tesis que se ha comprobado con creces es que a medida que el salario sea alto, los trabajadores tienen mayores niveles de competitividad, es decir, laboran en un clima de armonía y bienestar que se traduce de inmediato en buenos resultados para la empresa y en sí, también para el sistema.

En el caso particular de las empresas, éstas establecen como prioridad la implantación de salarios para sus trabajadores que no alcanza para cubrir sus necesidades económicas más apremiantes.

Es muy significativo al mismo tiempo la orientación que a últimas fechas se ha manifestado en los sistemas económicos: mientras menor sea el salario de los trabajadores, menor será el rendimiento del mismo, lo que se traduce en problemas graves tanto para la empresa como para el mismo trabajador.

Para la primera, sus productividades no serán las adecuadas y para los segundos, no tendrán suficiente dinero para satisfacer sus necesidades más apremiantes.

El caso del sistema económico mexicano es muy significativo, el aumento del salario mínimo se ha estancado en los últimos años (1996-2016), al grado de pugnar en el mes de noviembre del año 2016 la misma Confederación Patronal Mexicana (Coparmex) por un aumento sustancioso del salario en México del $30 \%$.

Es un hecho que nos debe orillar a reflexionar de manera objetiva, el que la misma clase patronal proponga aumentos significativos en el salario mínimo porque ve esa misma clase que el mercado interno en México está demasiado deprimido y se requiere una vitalización en el corto plazo.

El gran problema con el aumento del salario mínimo en México es lo referente a un incremento peligroso de la inflación, para ello, el gobierno en sus diversas dependencias debe ser muy cuidadoso en ello, máxima que en los últimos años se ha tenido una inflación controlada por las instancias correspondientes.

En Estados Unidos de América (USA), el salario mínimo para sus trabajadores está establecido en 120 pesos la hora, ${ }^{1}$ y si se trabaja un promedio de seis horas, el resultado será de 720 pesos al día. Si lo comparamos con el salario mínimo en México, éste está por el orden de los 75 pesos al día, es decir una proporción de casi 10 veces más por el salario en una hora con respecto al pagado por día en el país azteca.

\footnotetext{
${ }^{1}$ En el mes de noviembre del año 2016, algunos de los principales sindicatos de USA estuvieron promoviendo la propuesta de que aumentara el salario mínimo hasta los 14 dólares la hora, que al traducirlo a pesos mexicanos (a una paridad de 20 pesos por dólar) sería de 280 pesos la hora.
} 
En México el salario mínimo es de 75 pesos al día, una cantidad que a todas luces es insuficiente para el sostenimiento de una familia que debe satisfacer sus necesidades económicas mínimas como sería alimentación, vivienda y vestido. ${ }^{2}$

\section{PRINCIPALES INDICADORES}

El salario mínimo en México durante los últimos años ha tenido un incremento muy marginal si lo comparamos con el salario mínimo establecido en los países vecinos de USA y Canadá.

La idea fundamental de los tres sectores que definen el salario mínimo en el país mexicano ha sido siempre sujeto a un control irrestricto de la inflación, la cual ha estado por debajo del 10 por ciento en los últimos cinco años (2012-2016).

Si bien en términos macroeconómicos el control de la inflación ha sido controlado por las autoridades económicas en México, ello ha repercutido de manera negativa en los aumentos del salario mínimo, con un promedio anual de solamente el 3.0\% en términos generales.

La brecha entre el salario mínimo de México comparado con el pagado en USA y Canadá se aumenta año con año, en la medida que los aumentos en los dos países citados han sido más significativos, al grado de que en el año 2016 los principales sindicatos del país norteamericano están exigiendo un pago mínimo de 14 dólares la hora.

Lo anterior se refleja de manera puntual en la gráfica número 1 que se presenta a continuación.

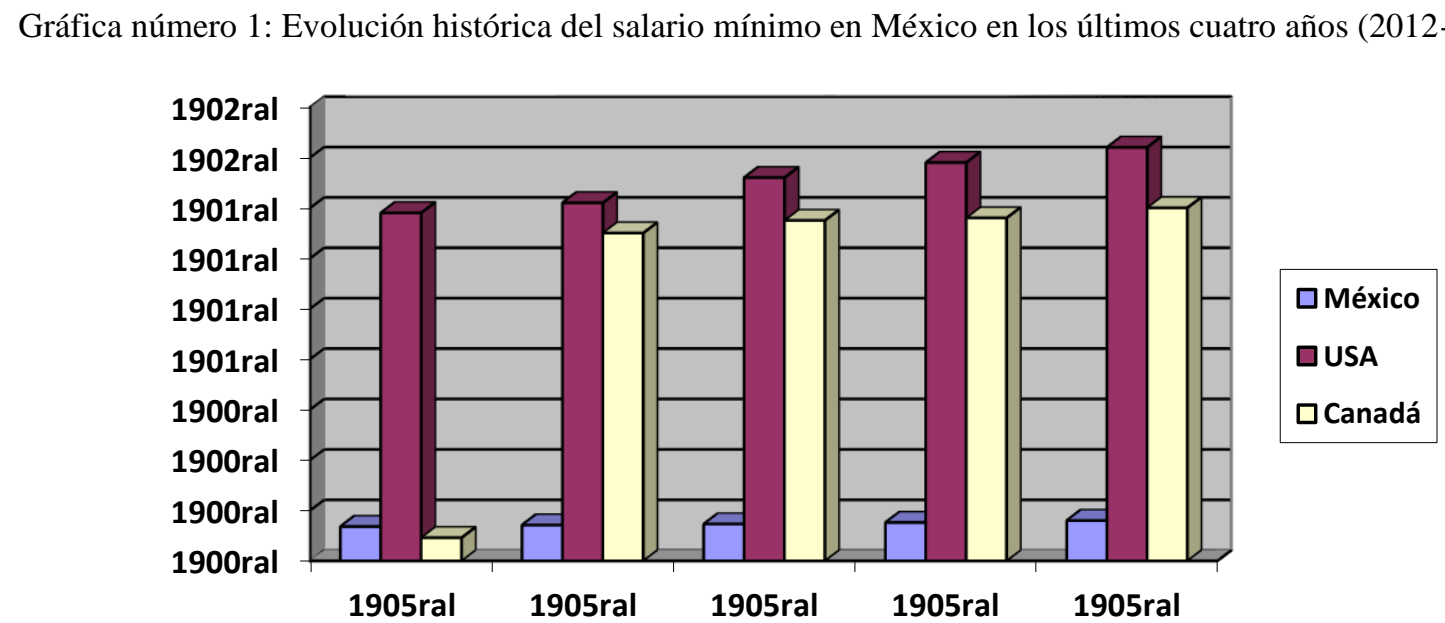

Fuente: elaboración propia con datos del Inegi, SHCP, SE, STPS y LEA UAZ, 2016

\footnotetext{
${ }^{2}$ El último aumento al salario mínimo se realizó el pasado jueves 1 de diciembre del 2016, aumentando a solamente 4.50 pesos en promedio por día, ubicándose en solamente 80.40 pesos diarios, una cantidad sumamente cuestionable por la sociedad mexicana.
} 
En la medida que el aumento del salario mínimo ha sido muy marginal en México (al no superar los 5 pesos al día), ello se traduce en un escaso poder de compra para la clase trabajadora mexicana, la cual debe realizar malabares con el magro salario que recibe mes con mes.

El grueso de los gastos de los que perciben salario mínimo en México se refleja en tres de los principales rubros de gastos como lo son alimento, vestido y pago a casa habitación.

La gráfica número 2 referida al comportamiento del gasto en tres rubros señala lo anterior.

Gráfica número 2, Gasto en tres rubros fundamentales para la población en México en los últimos años

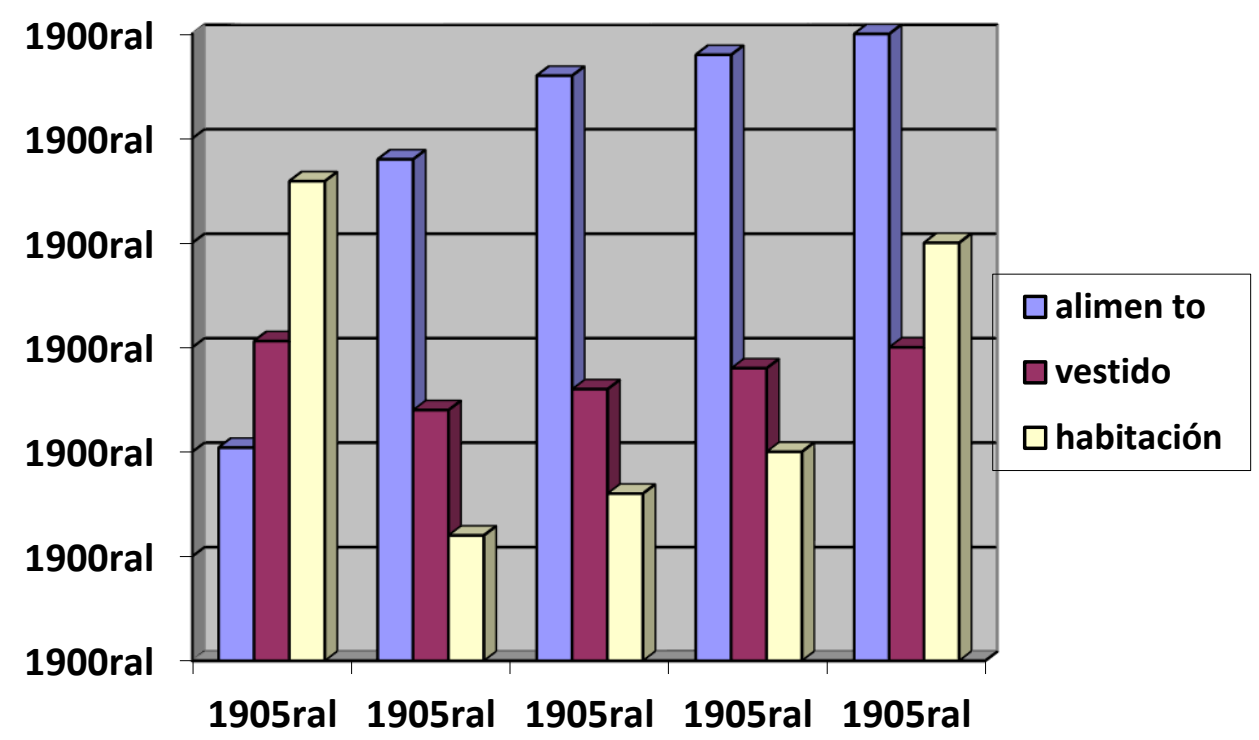

Fuente: elaboración propia con datos del Inegi, SHCP, SE, STPS y LEA UAZ, 2016

La gráfica número 2 indica la forma en la cual se distribuye el gasto de la población de menores recursos económicos (aproximadamente 8 millones de mexicanos), los cuales deben hacer rendir al máximo el escaso salario mínimo que perciben.

Asimismo, se hace notar que la alimentación sigue siendo la principal preocupación para el grueso de la población en México, seguido de la vestimenta y en menor medida la vivienda, aunque para el año 2016, los precios de las viviendas, tanto de renta como de compra se han elevado de manera significativa durante el año 2016.

En base a la información contenida en la gráfica número 2, se presenta a continuación un esquema que da cuenta de las erogaciones que realizan los trabajadores tomando en cuenta los satisfactores más elementales como lo son la alimentación, la vestimenta y la vivienda. 
Figura 1.- Esquema de gasto de los trabajadores que perciben un salario mínimo en México, en base a tres rubros: alimentos, vestidos y vivienda.

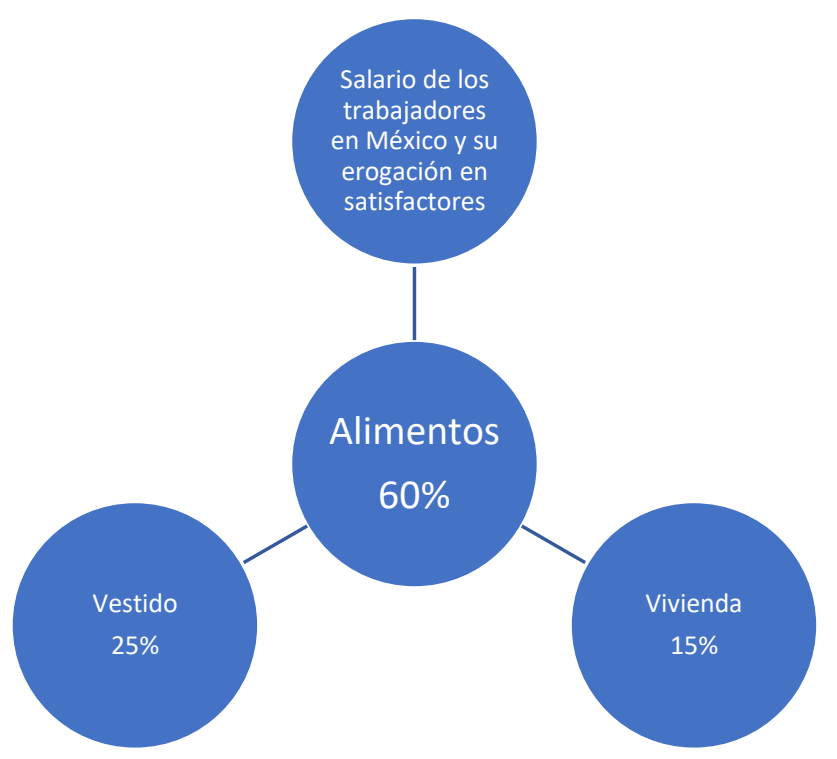

Fuente: elaboración propia, 2016

Los trabajadores deben erogar en otros rubros como serían esparcimiento y diversión, sin embargo, el monto del salario en México para un segmento considerable de la población se deja de lado en la medida que la cantidad percibida de pago por sus servicios no es lo suficiente para gastar en notros rubros como los ya señalados.

A continuación, se presenta la figura número 2, que establece tres estratos poblacionales en México que perciben salarios, se caracterizan por tres: alto, medio y bajo de acuerdo a sus niveles salariales: el alto ingresos por arriba de los 60 mil pesos al mes, el medio con un promedio de salarios que abarcan los 25 mil pesos al mes y el estrato bajo que alcanza los 6 mil pesos mensuales.

Figura número 2.- Estratos de trabajadores que perciben salarios altos, medios y bajos en México.

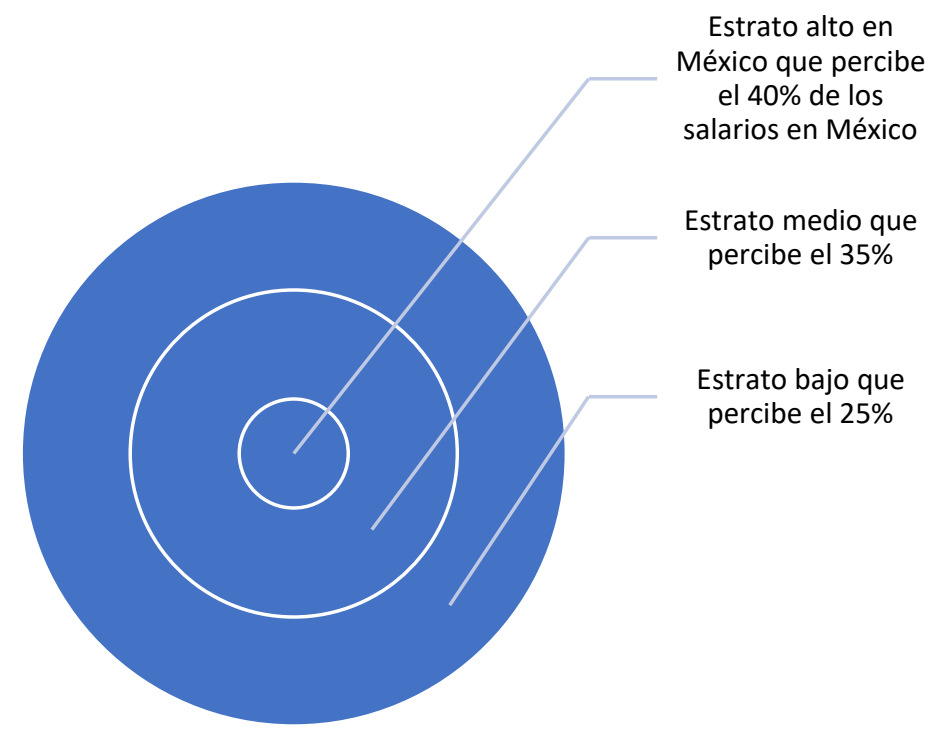

Fuente: elaboración propia, 2016 
El grueso de los montos salariales se los proporcionan a la clase alta, la cual en promedio recibe un salario mensual de 60 mil pesos.

La clase medio está en el orden de los 30 mil pesos mensuales.

La clase baja está percibiendo en promedio un salario mensual de 6 mil pesos.

Un indicador de la población en México que percibe salario mensual y cuenta con trabajo fijo y duradero (base) lo constituye el lugar en el cual realiza sus principales compras de alimento y vestido, ello se refleja en el esquema número 2.

Este esquema es resultado de investigación empírica realizada en el LEA de la UAEUAZ, México en base a entrevistas periódicas aplicadas en los principales centros comerciales de la zona conurbana Guadalupe-Zacatecas, la periodicidad está en función de dos meses o de acuerdo a diversas ocasiones de compras masivas que tienen los consumidores, particularmente los meses de abril (semana santa), julio y agosto (vacaciones de verano) y la época navideña (diciembre y enero).

Figura 3.- Espacio donde se realizan las principales compras de los trabajadores que perciben un salario mínimo en México El 58\% adquiere sus satisfactores en las tiendas de autoservicio ubicadas en zonas macros

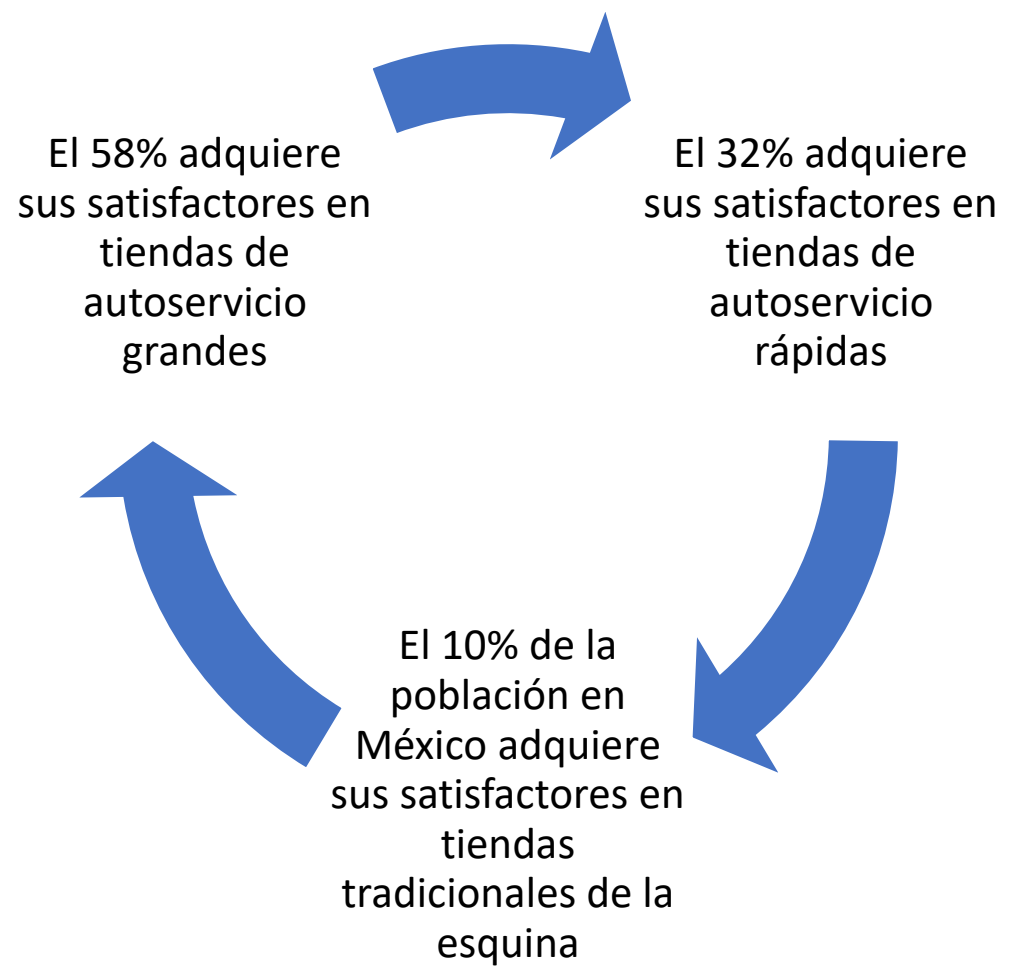

Fuente: elaboración propia, 2016

Es indudable que las tiendas de autoservicio de gran escala están absorbiendo al grueso de los compradores de la población mexicana que requiere adquirir sus satisfactores alimenticios de manera cotidiana. Un caso particular que cada vez se manifiesta en mayor medida es el referente a la desaparición 
gradual de las tiendas de abarrotes tradicionales, las cuales a pesar de los esfuerzos porque no desaparezcan, la competencia de las tiendas de autoservicio cada vez se manifiesta en mayor medida. ${ }^{3}$

\subsection{COMPARACIONES DEL SALARIO MÍNIMO EN MÉXICO DURANTE EL SEXENIO 2012-} 2016.

En el sistema económico mexicano 8.4 millones de trabajadores sobreviven con un pobre salario mínimo de 2,228 pesos al mes. Sin embargo para instituciones gubernamentales como la CONEVAL, ${ }^{4}$ la canasta básica (alimentaria y no alimentaria ${ }^{5}$ ) se cubre con 2,695 pesos al mes, es decir, con el insuficiente salario mínimo que percibe el 16\% de la población ocupada en México, hacen falta 467 pesos para cubrir las necesidades económicas más elementales de la 8.4 millones de trabajadores.

Esta diferencia la hemos calculado en base a investigaciones periódicas que realizamos en el Laboratorio de Economía Aplicada (LEA) de la Unidad Académica de Economía de la Universidad Autónoma de Zacatecas, México, con información periódica de INEGI, SE, STPS, SHCP, Banco de México.

La brecha entre los que menos ganan y los que detentan la riqueza económica en el país mexicano según la $\mathrm{OCDE}^{6}$ hace que México sea uno de los países más desiguales del mundo. El 65\% de la riqueza del país azteca en solamente el 10\% de las personas más ricas de la población, reporte de Global Wealth Report 2015.

Aún más, el índice de Gini que es un indicador que cuantifica la inequidad de los ingresos es de $0.52 \%$. El índice señalado establece que entre más cerca se esté de uno, mayor grado de concentración del ingreso se tiene.

El siguiente cuadro número 1 nos demuestra lo especificado líneas atrás.

Cuadro número 1.- Concentración del ingreso en el $1 \%$ de la población para seis países, año 2016
\begin{tabular}{|l|c|}
\hline PAÍS & MONTO \\
\hline México & 23 \\
\hline Colombia & 22 \\
\hline USA & 6.8 \\
\hline Suecia & 6.2 \\
\hline Dinamarca & 6 \\
\hline China Fuente: Elaboración propia LEA 2016
\end{tabular}

\footnotetext{
${ }^{3}$ Los casos de las tiendas OXXO son más que significativos en todo lo largo y ancho del país.

${ }^{4}$ Consejo Nacional de Evaluación para la Política de Desarrollo Social, CONEVAL.

${ }^{5}$ Gastos en Transporte, cuidado personal, educación y esparcimiento.

${ }^{6}$ Organización para la Cooperación y el Desarrollo Económicos.
} 
Esta gran desigualdad está ligada de manera directa con el salario que se percibe en los países señalados, sobre todo en los más bajos como es el caso de México. La consecuencia más inmediata de no incrementar adecuadamente los salarios en los países se traduce en el pobre crecimiento económico que no sobrepasa en los últimos 20 años al 3\% (en promedio durante los últimos cuatro años de administración del presidente EPN el crecimiento ha sido de solamente el $2.3 \%$ anual).

Esquivel (2016) establece que ...la desigualdad afecta las posibilidades de crecimiento de la economía en la medida en que esto va acompañado de amplios sectores de la población cuya capacidad de compra es pequeña. Eso contribuye a debilitar el mercado interno ${ }^{7}$

El bajo nivel del salario mínimo en México ha servido solamente como una contención de la subida de los precios de los bienes y servicios, es decir, una constante lucha porque la inflación no llegue al 10\% y se mantenga entre el 3 y el 4\% en promedio durante los últimos cinco años (2012-2016).

Sin embargo, es necesario argumentar en este punto que el control de la inflación por parte de las autoridades económicas de México se ha realizado a costa de los trabajadores, el siguiente dato referido al poder adquisitivo nos indica que en el año 2005 el salario era de 1,782 pesos al mes y para el año 2016 ha disminuido hasta 1,689 pesos.

Una de las principales preocupaciones de la clase gobernante en el sexenio actual la constituye el que se preocupa en demasía por controlar la inflación, argumentando de manera constante que es una de las principales variables económicas que se ha manejado de manera adecuada al ubicarse por debajo del $10 \%$.

También es necesario resaltar que dicha variable no ha sido del todo homogénea para los productos de mayor consumo y sobre todo en diversas épocas del año. Ejemplo de ello lo tenemos en los aumentos desproporcionados de ciertos artículos consumidos de manera periódica y en gran escala como el limón, aguacate y jitomate.

Este tipo de productos varían en su precio de manera muy desordenada en los mercados del país, al grado de ser uno de los causantes mayores de los índices inflacionarios que han superado el 30 por ciento en algunas ocasiones.

\footnotetext{
${ }^{7}$ Esquivel G., Desigualdad Extrema en México. Concentración del poder económico y político, publicado por OXFAM, 2015
} 


\subsection{ALGUNOS PAÍSES QUE PERCIBEN SALARIOS MÍNIMOS POR HORA EN TÉRMINOS DE DÓLARES NORTEAMERICANOS}

México es el país que para el año 2016 percibe el salario por hora más bajo comparado don nueve países de diversas regiones, entre los que destacan China, Brasil, Chile, Venezuela, España, Canadá, Usa, Luxemburgo y Australia. La gráfica siguiente da cuenta de lo anterior.

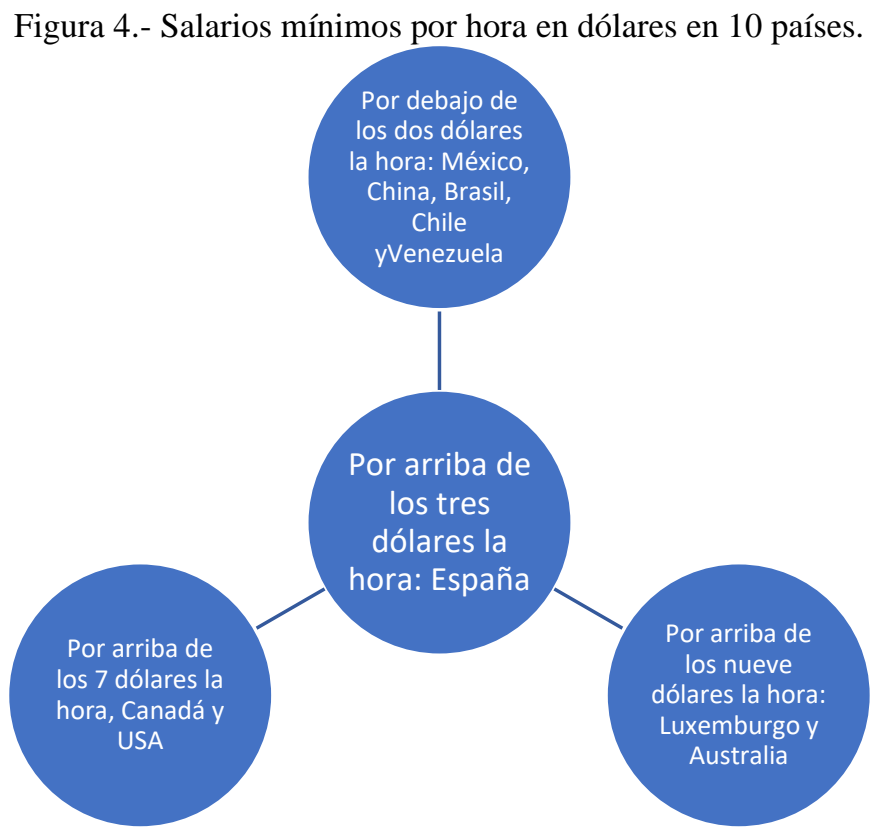

Fuente: elaboración propia, 2016

La figura número 4, refleja de manera puntual la enorme diferencia entre nueve países con respecto a México, un salario de 40 dólares la hora equivale a solamente 8 pesos la hora (con la proporción de 20 pesos por dólar), una cifra muy por debajo de China que tiene un pago por hora de 14.80 pesos la hora, asimismo el país latinoamericano que paga mejor a sus trabajadores la hora es Venezuela con 30.20 pesos la hora, ${ }^{8}$ Usa paga 145 pesos la hora y por último Australia tiene la mayor proporción de pago por hora de sus trabajadores que resulta en 190.8 pesos la hora.

La diferencia notable entre los países señalados comparándolos con México nos demuestra claramente que en algunos de esos países el desarrollo económico es notable, sobre todo en el país asiático de China que tiene niveles de crecimiento por arriba del $7 \%$ anual.

Asimismo, se corrobora de inmediato que el país de Australia tiene las mejores condiciones de trabajo en estos momentos, esto es, se paga en términos de salario mínimo por arriba de USA o Canadá y la diferencia con referencia a México es muy notoria.

\footnotetext{
${ }^{8}$ Aunque debemos hacer notar que el salario más alto en Latinoámerica como lo es el pagado en Venezuela se erosiona muy fácilmente con la espiral inflacionaria que no se ha podido controlar en varios años y que se acentúa en el presente 2016.
} 
Los datos son resultado de una consulta que se realizó en diversas instancias como la OCDE, ${ }^{9}$ Bloomberg y LEA en el mes de noviembre del año 2016, y corroborado en el periódico La Jornada sección Dinero a cargo de Enrique Galván Ochoa. El cuadro número 2 es resultado de ello.

Cuadro número 2.- Salario pagado por hora en dólares en diez
\begin{tabular}{|lc|} 
Primer lugar mundial \\
en salarios... bajos \\
\hline México & \\
China & .44 \\
Brasil & .74 \\
Chile & .90 \\
Venezuela & 1.45 \\
España & 1.51 \\
Canadá & 3.40 \\
Estados Unidos & 7.18 \\
Luxemburgo & 7.25 \\
Australia & 9.24 \\
\hline * Salario mínimo por hora en dólares de Estados Unidos & 9.54 \\
Fuente: OCDE, Bloomberg.
\end{tabular}

Resultado del cuadro anterior, se presenta la gráfica número 3 que da cuenta de manera puntual el comportamiento que ha tenido en al año 2016 los salarios pagados por hora en México comparado con 9 países en términos de dólares.

Es el más bajo de los países señalados

Gráfica úmero 3, salario por hora en dólares para 10 países, año 2016

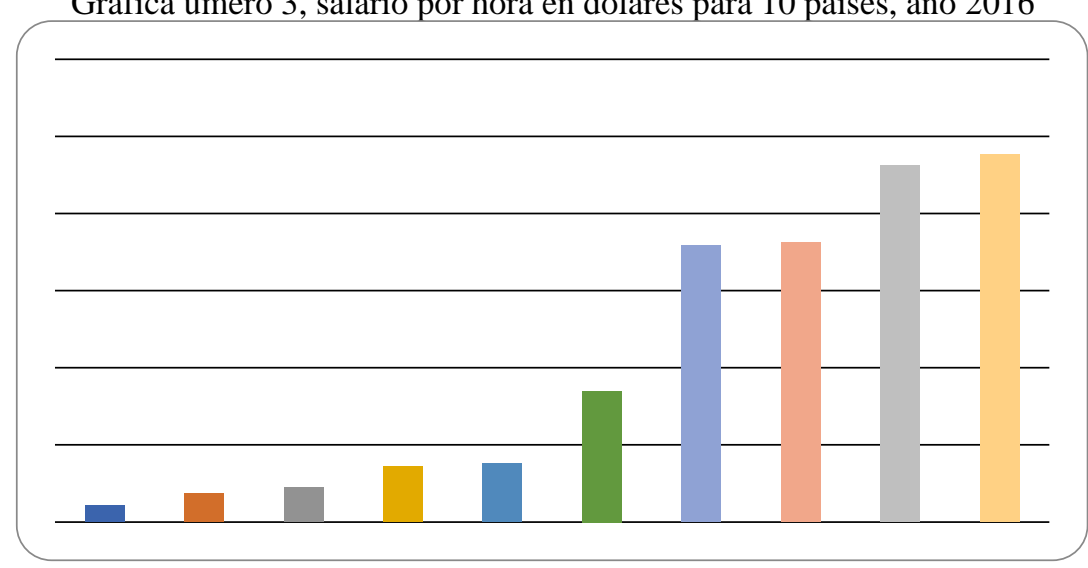

Fuente; elaboración propia con datos del cuadro número 1, 2016.

En la Constitución Política de los Estados Unidos Mexicanos, se establece de manera puntual que el salario mínimo debe satisfacer las necesidades materiales, sociales y culturales de un jefe de familia, además de cumplir con la educación obligatoria a los hijos. ${ }^{10}$

\footnotetext{
${ }^{9}$ Organización para la Cooperación y el Desarrollo Económicos

${ }^{10}$ Artículo 123 de la Constitución Política de los Estados Unidos Mexicanos.
} 
Debemos anotar que incrementos en los salarios mínimos adecuados, aumentan la productividad, se tiene menor rotación en las empresas y en sí, la empresa y el trabajador ganan en mayor bienestar.

Una de las principales características de los países desarrollados en el mundo ha demostrado que al subir el salario de sus trabajadores, también aumenta la línea de bienestar y con ello el Producto Interno Bruto se acrecienta en un $1 \%$ anual de manera directa en la medida que el dinero desembolsado por los empleadores va directamente a consumir bienes y servicios básico, fortaleciendo desde luego al mercado interno y pudiese ser que también alentaría a que los trabajadores informales pasaran a la formalidad en menor tiempo.

Una consecuencia inmediata de aumentos en los salarios mínimos adecuada reduce de inmediato los niveles de desigualdad que se tienen en los sistemas económicos, particularmente de México en los últimos cinco años.

El gran desafío que se tiene en México si se aumentasen los salarios mínimos por arriba de los 90 pesos diarios se ha detenido con el anuncio de que solamente se pagarán a partir del primer día del mes de enero del año 2017 solamente 80.40 pesos al día como salario mínimo, una cantidad a todas luces insuficiente para cubrir las necesidades económicos de los trabajadores que son más de 8.5 millones.

\section{CONCLUSIONES}

1.- El salario mínimo en México es de los más bajos en el mundo.

2.- Un salario mínimo insuficiente para la clase trabajadora implica disminución de la productividad en las labores que desempeña.

3.- Escaso salario implica afectación en el crecimiento económico del sistema en la medida que se deprime el mercado interno por la falta de dinero suficiente para adquirir bienes y servicios.

4.- Salario mínimo insuficiente es resultado de una gran desigualdad salarial en el sistema económico mexicano.

5.- El escaso pago a los trabajadores en México es resultado de una política económica que favorece a los que más tienen y perjudica a millones de trabajadores.

6.- Casi 9 millones de trabajadores perciben un salario mínimo de 75 pesos al día para el año 2016.

7.- El aumento del salario mínimo en México para el año 2017 será de 80.4 pesos por día, una cantidad insuficiente para adquirir lo indispensable para subsistir.

8.- Un salario mínimo adecuado (200 pesos al día), aumentaría la productividad de los trabajadores en México. 


\section{BIBLIOGRAFÍA}

Constitución Política de los Estados Unidos Mexicanos, 2014, México.

Laboratorio de Economía Aplicada LEA, varios años, Unidad Académica de Economía de la UAZ, 2016, México.

INEGI, varios años, 2016, México.

Laboratorio de Economía Aplicada, UAEUAZ, 2016, México.

Periódico El Sol de Zacatecas, varios años, sección Economía y Análisis, México.

Periódico la Jornada, sección Dinero, Enrique Galván Ochoa, noviembre del 2016, México.

Piketty T., El capital en el siglo XXI, Ed. FCE, 2014, México.

Revista Expansión, noviembre 15, 2016, año XLVIII, número 1201, México. , junio 15, 2016, año XLVIII, número 1201, México.

Robles, S. Alcances y limitaciones del neoliberalismo en México y Zacatecas 2000-2014, Ed. UAZ, 2015, México. 